\title{
SOME EXPERIENCES WITH NON-TRAUMATIC PARAPLEGIA IN MALAYSIA
}

\author{
By Prof. J. Francis Silva \\ Orthopaedic Department, University Kuala Lumpur
}

Hzalth problems in developing countries are so very different to those in the Western world. To mention but a few examples poliomyelitis and tuberculosis still occur in numbers to cause concern. To counter this, however, the incidence of traumatic paraplegia is not as high as it might be, except for those unfortunate individuals who fall from trees or buildings, in the course of their occupation.

Malaysia, however, is almost at a crossroads and is having the best of both worlds what with rapid industrialisation and the opening of the country with wider and better roads. Traumatic paraplegia is not an infrequent occurrence while at the same time there is a high incidence of non-traumatic paraplegia.

\section{ANALYSIS OF MATERIAL}

In the period 1967 to I97I, I4I patients with non-traumatic paraplegia were admitted to the University Hospital, Kuala Lumpur, for operative treatment. Table I illustrates the analysis of these patients according to age, sex and aetiology.

\section{TABLE I}

Analysis of I4I patients according to age, sex and aetiology.

\begin{tabular}{|l|c|c|c|c|c|c|c|}
\hline \multirow{2}{*}{ Aetiology } & \multicolumn{2}{|c}{ I2 years and below } & Above I2 years & \multicolumn{2}{c|}{ Total } \\
\cline { 2 - 8 } & Male & Female & Male & Female & Male & Female \\
\hline Hansen's disease & - & 2 & 29 & II & 29 & I3 \\
\hline Poliomyelitis & I & 9 & 8 & 6 & 22 & I 5 \\
\hline Pott's paraplegia & 5 & 2 & Io & 5 & I5 & 7 \\
\hline Cerebral palsy & 9 & 5 & 3 & 3 & I2 & 8 \\
\hline Spinal cord tumour & I & 2 & 4 & 6 & 5 & 8 \\
\hline Spinal bifida & 5 & I & I & & 6 & I \\
\hline Total & 34 & 2I & 55 & 3 & 89 & 52 \\
\hline
\end{tabular}

Hansen's disease, though producing only paralytic manifestations below the knees, was the largest group. There were 37 patients with poliomyelitis tuberculosis 22 and cerebral palsy 20 patients. Many of these did not receive treatment 


\section{TABLE II}

Aetiology of non-traumatic paraplegia as well as age distribution Non Traumatic Paraplegia, University Hospital 1968-April 1972

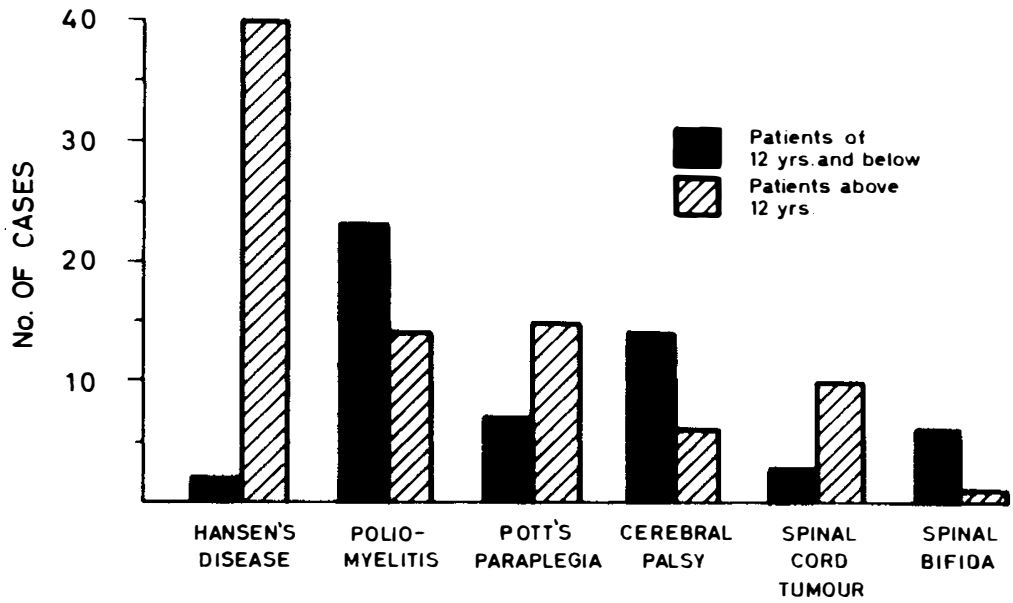

TABLE III

Ethnic distribution

Ethnic Distribution of 141 Non-Traumatic Paraplegia Cases from 1968-April 1972, University Hospital

TOTAL 141 CASES
\begin{tabular}{|c|c|c|c|}
\hline Malay & Chinese & Indian & Others \\
\hline 20 & 79 & 32 & 10 \\
\hline
\end{tabular}

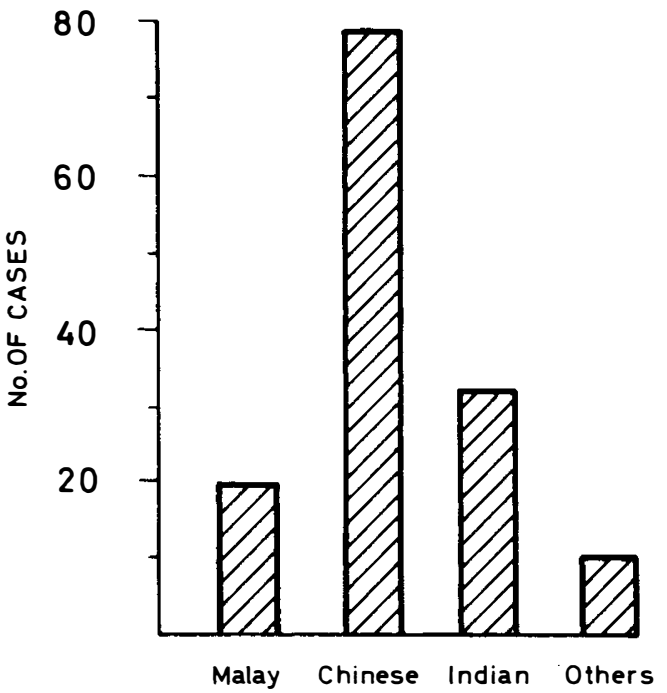


until very late, having lived with their physical disability for many months or even years.

Table II illustrates the aetiology of non-traumatic paraplegia as well as age distribution. Eighty-six patients were over I2 years of age, while 55 were under that age.

Table III illustrates the ethnic distribution, while Table IV analyses the age distribution in greater detail.

TABLE IV

Analysis of age and sex distribution in greater detail

Age Distribution of 141 Patients of Non Traumatic Paraplegia

in the University Hospital from 1968-April 1972

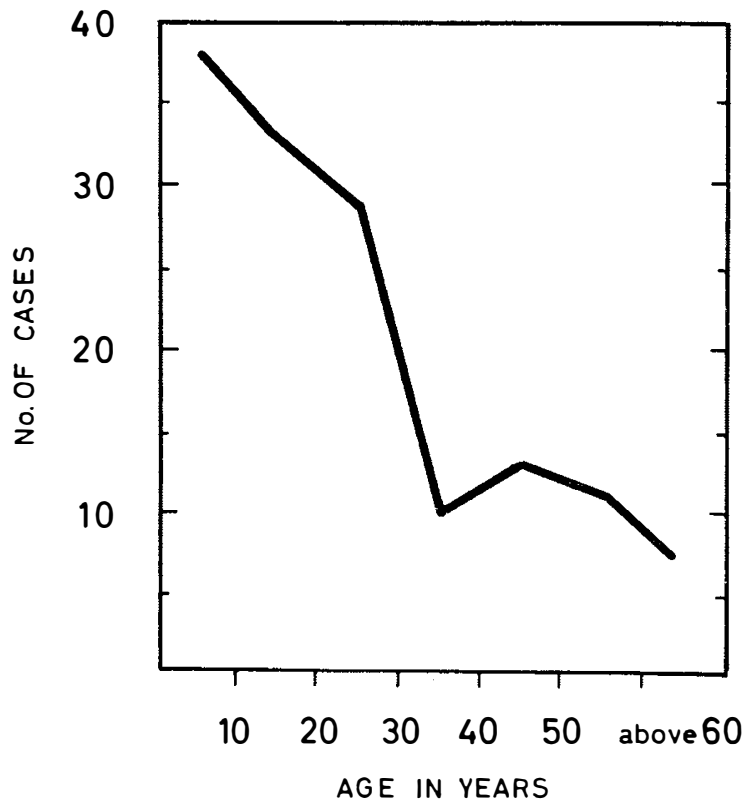

Poliomyelitis. Residual paralysis of both lower extremities after an attack of acute anterior poliomyelitis is not uncommon. This will be a continuing problem in Malaysia owing to the recent outbreak of epidemic poliomyelitis. Three hundred and six cases were reported in I97I. The complete breakdown of these patients is not yet available. However, there have been 47 cases with residual paralysis in one District Hospital alone. However, to emphasise this problem in developing countries, Table $\mathrm{V}$ shows the analysis of cases in Ceylon during the period 1962 to 1970 . This has been so, even with a reasonable island-wide immunisation programme. Consequently, resulting from the current outbreak, paraplegic problems will arise in the years to come as well as from possible future epidemics (Silva, I97I). 
PAPERS READ AT THE ANNUAL SCIENTIFIC MEETING, I 972

TABLE V

Analyses the cases of poliomyelitis in Ceylon

\begin{tabular}{|c|c|c|c|c|c|c|}
\hline \multirow[b]{2}{*}{ Degree of disability } & \multicolumn{6}{|c|}{ Number of incidence } \\
\hline & 1962 & I963-66 & 1967 & I968 & I969 & I970 \\
\hline Nil & 569 & 210 & 30 & I2I & \multirow{6}{*}{$\begin{array}{l}\text { Not } \\
\text { available }\end{array}$} & 23 \\
\hline Mild & 374 & 227 & 32 & I 73 & & I7 \\
\hline Moderate & 256 & I7I & 22 & 176 & & I 2 \\
\hline Severe & I 53 & 72 & 8 & II 6 & & 4 \\
\hline Total cases assessed & 1352 & 680 & 92 & 586 & & 56 \\
\hline Total cases notified & I8IO & IIO3 & I 44 & 1009 & & I $2 \mathrm{I}$ \\
\hline
\end{tabular}

Assessment made at the end of 2 months of onset of illness.

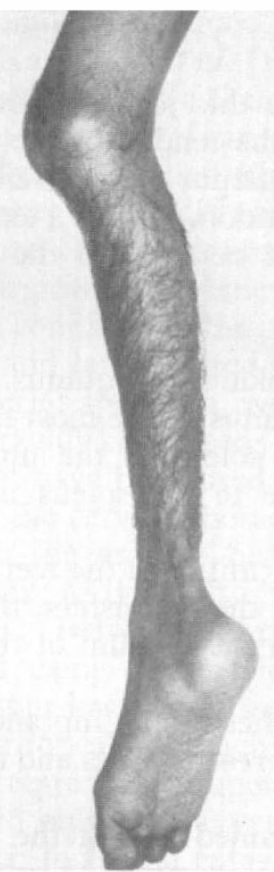

FIG. I
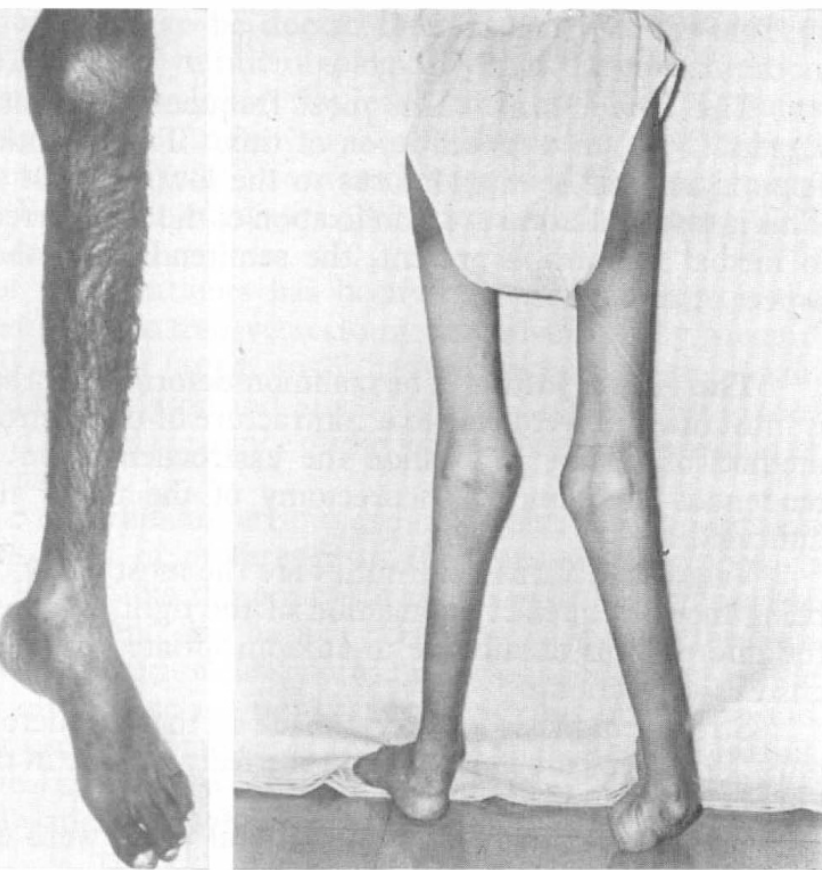

FIG. 2

FIG. I.-Shows a case of flexion contracture at both hips and knees.

FIG. 2.-Case of left calcaneo-varus and right calcaneo-valgus deformities. 
There were 442 patients with poliomyelitis seeking treatment in the period from July I967 to April I972. In this group there were 70 paraplegic patients, 37 of whom were operated on.

The ethnic distribution is significant in that the highest incidence is among the Chinese and Indian communities as compared with the Malays. This may well be due to the fact that these communities live in crowded urban areas with less chance of auto-immunisation as opposed to the rural Malay.

The commonest operations have been for the correction of flexion contractures at the hips and knees and equines and the ankle. Figure I shows such a case. Figure 2 illustrates another with a left calcaneo-varus and right calcaneo-valgus deformities. After surgery, ambulation has been successfully affected by an intensive programme of rehabilitation with surgical appliances when indicated.

\section{OPERATIVE PROCEDURES}

The Hip Joint. The commonest problem at the hip has been mild flexion and adduction deformity. These have been corrected by an adductor tenotomy and a neurectomy of the anterior division of the obturator nerve. When this deformity is associated with long-standing flexion contracture, elongation of the iliopsoas is insufficient and the muscles attached to the iliac crest have to be divided. Very rarely an extension or rotation osteotomy may be indicated when the deformities are severe and of long standing. Iliopsoas transfer has been used in two cases (Sherrard, 1944).

The Knee Joint. The most frequent operation on this joint has been an Eggers (1952) or a modification of this. Transplanting the tendon of the biceps femoris and the semitendinosus to the lower end of the femur being preferable. This is essential to ensure firm fixation of the transferred tendon. When a tendency to medial rotation is present, the semitendinosus should be fixed to the lateral aspect of the femur.

The Ankle Joint. The common deformity at the ankle is an equinus. This is most often due entirely to a contracture of the gastrocnemus. The most feasible method of release is to slide the gastrocnemus on the soleus at the muscular tendenous junction. A neurectomy of the upper nerve to the soleus may be indicated.

Valgus and varus deformities are the most likely deformities in the feet, varus being more frequent. Elongation of the tight tendons or their transfers, through the interosseous membrane to an appropriate position on the dorsum of the foot ensures correction.

Strong emphasis has to be made in that the deformities of the hip and knee must be corrected before those in the feet, as done in the present series and also by Pollock and English (1967).

Eighty-eight patients with cerebral palsy were examined during the period under review. In this group, there were 36 paraplegics. Following the principles just discussed only 20 patients underwent operative treatment. The most common operations being release of flexion adduction at the hip and hamstring transfers at the knee. 
Pott's Paraplegia. Paraplegia due to spinal caries is an age-old story. Credit is given to Sir Percival Pott (I 779) as being the first to describe it accurately, though Delchamps (I570) and Severinus (I632) have described the condition earlier (Hodgson \& Arthur, 1967).

The condition has been classified into two categories (Sorrel \& Sorrel, I923). Should a patient get paraplegia within the first 2 years since the onset of spinal caries it is referred to as early onset paraplegia. Conversely, if the onset of neurological symptoms were manifested after this period, it was referred to as late onset paraplegia. This classification has since been altered and modified (Griffiths et al., 1956) and more recently still by Hodgson and Arthur (1967).

The neurological manifestations in the early type are mostly due to pressure effects of the abscess and/or 1ts contents. A tuberculosis meningo-myelitis is another possibility (Hodgson \& Arthur, I967). In management, the advantages of early surgery have been stressed by several workers (Wilkinson, I955; Silva, 1958, 1964; Hodgson et al., 1964, I965, 1967; Kirkaldy et al., 1965).

The futility of conservative management is evident when the results of such treatment are evaluated. In a series of patients with spinal tuberculosis without paralysis, managed conservatively with posterior spinal fusion, showed that only 65 per cent. were back at their normal work after 5 years. In another series it was only about 53 per cent. after a 5-year follow-up without spinal fusion (Girdlestone \& Somerville, 1952), how then would it be in the unfortunate paraplegic?

Chemotherapy does not alter the role of surgery. Lindberg (1967) has shown that the concentration of streptomycin in tuberculosis pus was very variable. Hever and Risko (I969) thought this to be due to the chronicity of the abscess wall. Katayama et al. (I930) have shown microbiologically that the concentration of streptomycin in a skeletal tuberculous lesion was less than in the blood, $\mathrm{I} \frac{1}{2}$ hours after an injection of streptomycin $\frac{1}{2} \mathrm{~g}$. Andre (1956) also showed similar findings using litrium labelled dihydrostreptomycin. Conversely izoniazed has been shown to be more freely diffusible (Barclay et al., 1953). He emphasises the need for a combined chemotherapeutic regime.

Surgical management of these patients has been dependent largely on the general condition of the patient. Costo transversectomy first advocated by Menard (I900) and later revised by Wilkinson (1954, 1956) has hardly been used. Again the anterior approach, evolved by Hodgson and Stock (1956), Hodgson et al. (I960) and Kirkaldy et al. (1965) for a radical clearance of the lesion and decompression of the cord have been used extensively.

In the cervico-thoracic level, a difficult area to explore, a pericapsular incision through the 3 rd rib bed was used in preference to the trans-sternal approach (Cauchoix \& Benet, 1957). Below this the approach is through the appropriate rib beds. Between the I2th dorsal and 2nd lumbar vertebrae excision of the II th rib and using a transpleural extraperitoneal approach with mobilisation of the diaphragm has been used or alternatively a transpleural, transdiaphragmatic and extraperitoneal approach was used in some cases (Kirkaldy et al., 1965). In this lumbar region an extraperitoneal approach was used. Anterio-lateral decompression was used only for the very ill patients in whom it was considered the transpleural approach to be too extensive. It has been convincing that the anterior approach gives a clearer picture of the pathology and provides for better decompression, although the limited exposures have their advocates (Goel, 1967; Guirguis, I967). 
Age. Although Seddon (1935) and Sorrell and Sorrel (1923) claimed that age had no bearing on the prognosis, Hodgson et al. (1964), with their wider experience, claimed a better prognosis for the younger age groups. This has been the experience in the present series.

Thirty-four patients with spinal tuberculosis were admitted for treatment, 22 of whom were paraplegic (Table VI). The higher incidence of paraplegia is an indication of the tendency among patients to resort to indigenous remedies as the first line of action. They attend hospital only when weakness of the lower extremities begins to manifest itself.

Anterio Lateral Decompression (seven patients) was performed only when the patients were in poor general health.

\section{TABLE VI}

Analysis of cases of spinal tuberculosis

No. of cases with paraplegia

No. of cases without paraplegia

Total no. of spinal tuberculosis cases

\section{TABLE VII}

Analysis of operations done for Pott's paraplegia

\begin{tabular}{|c|c|}
\hline Types of operation & No. of cases \\
\hline Antero-lateral decompression & 7 \\
\hline $\begin{array}{c}\text { Anterior decompression, transpleural } \\
\text { without spinal fusion }\end{array}$ & 4 \\
\hline $\begin{array}{l}\text { Anterior decompression, transpleural } \\
\text { with spinal fusion }\end{array}$ & II \\
\hline Total & 22 \\
\hline
\end{tabular}

Transpleural Decompression Without Fusion (four patients). In these again, the spine was stable and their general condition did not warrant exposure of the iliac crest for grafts.

Transpleural Decompression With Fusion (I I patients). Table VII analyses the operations done for Pott's paraplegia in the present series. Figure 4, A and B shows X-rays of one of the cases of paraplegia with lesions at the I Ith dorsal and Ist lumbar vertebrae.

Table VIII illustrates the duration of stay of all cases of spinal tuberculosis, the average being 14.5 weeks.

There have been no fusion failures in the small series. Complete recovery was effected in all patients except two who had to use long leg calipers. The latter had fixed kyphotic deformities corrected by helo-pelvic traction after decompression. 
FIG. 3.-Shows a transpleural decompression.

FIG. 4.-X-rays of a patient with disease at the I Ith dorsalIst lumbar vertebrae resulting in paraplegia.

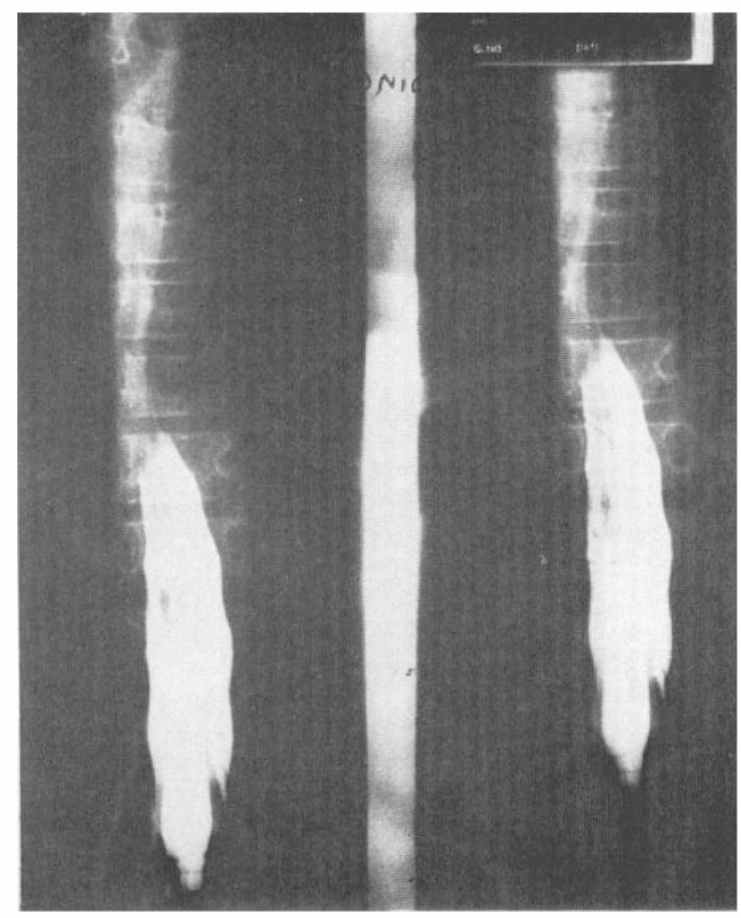

FIG. 3
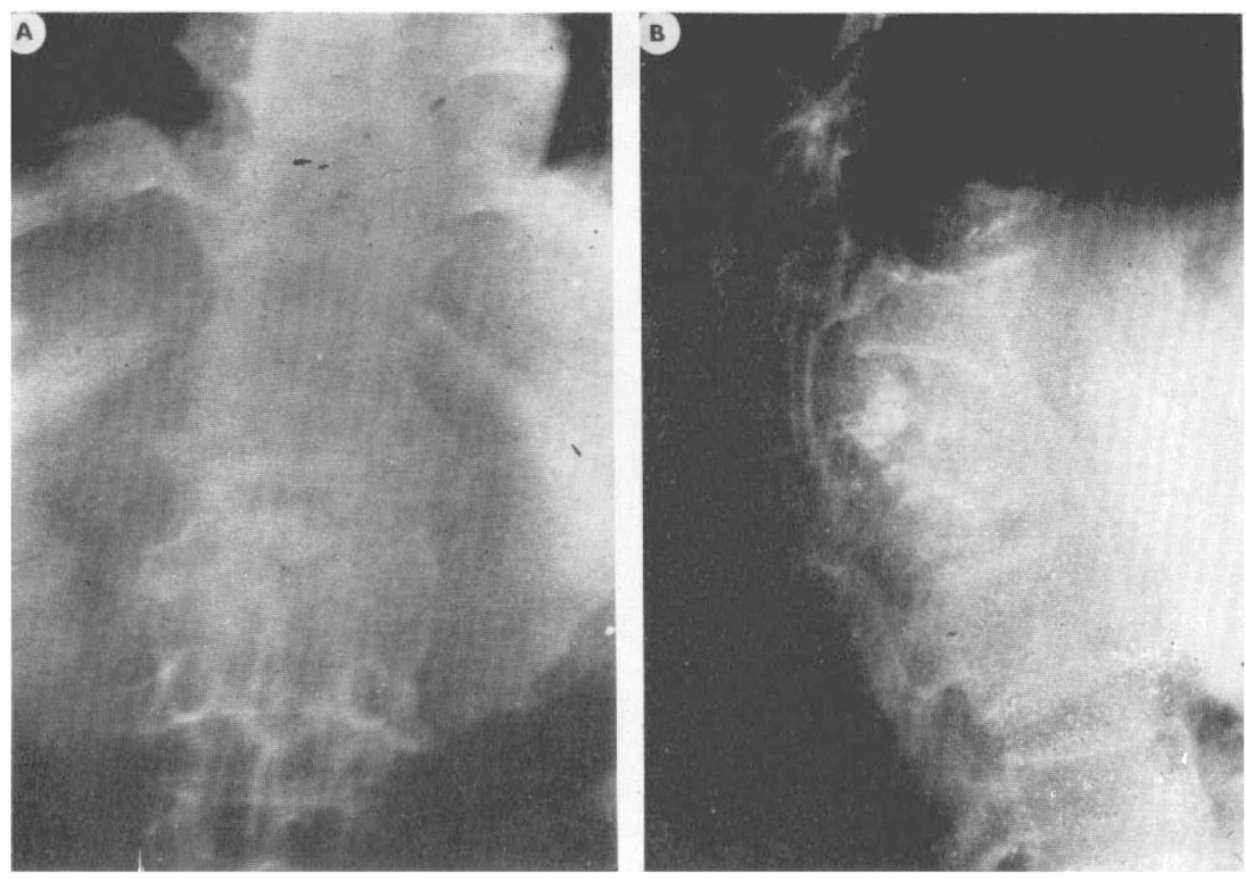

FIG. 4 I I $/ 2-M$ 
TABLE VIII

Duration of stay of all cases of spinal tuberculosis

Maximum hospital stay $\quad 60 \cdot 0$ weeks

Minimum hospital stay $2 \cdot 0$ weeks *

Average hospital stay $\quad 14.5$ weeks

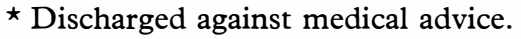
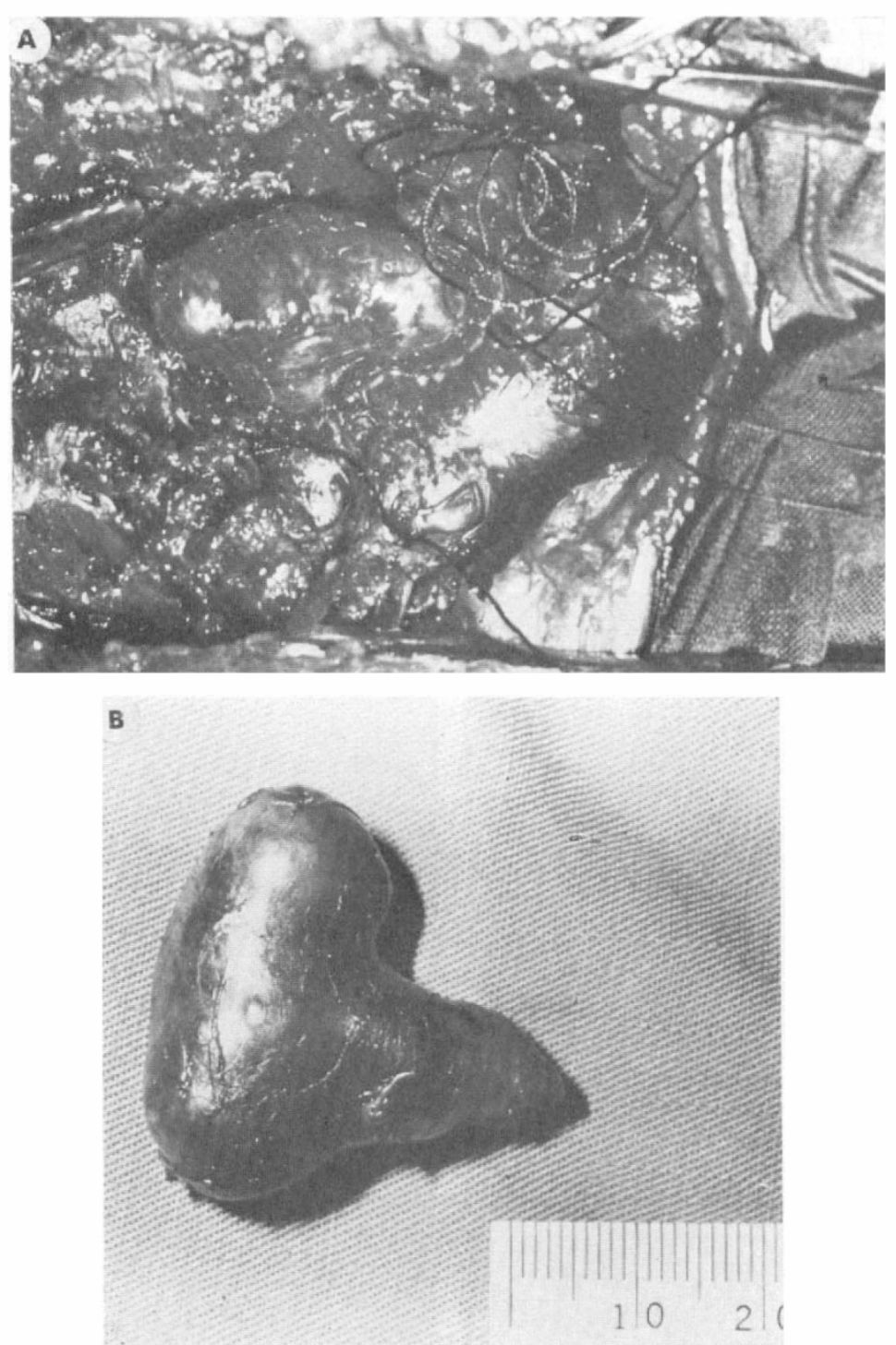

FIG. 5

A neurofibroma of the spinal cord at operation and after removal. 


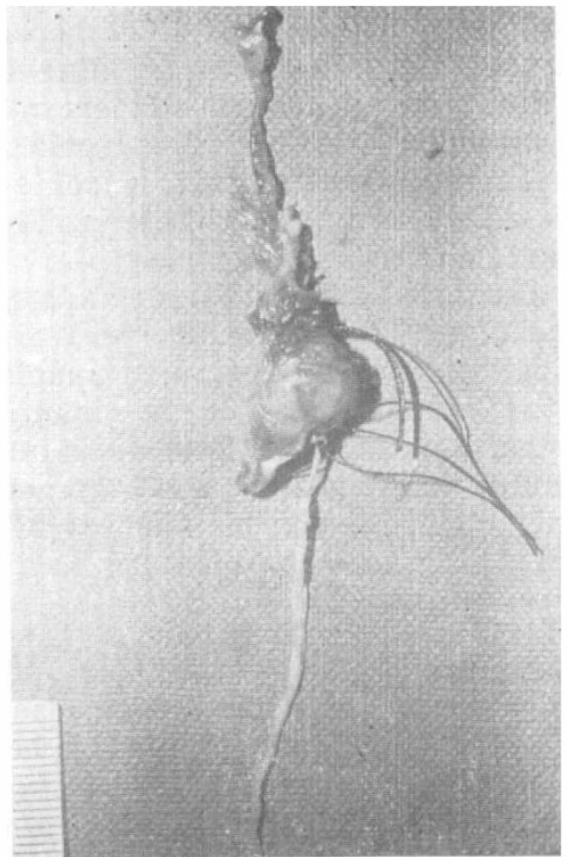

FIG. 6

A case of dermoid cyst of lumbar spine during operation, the specimen and after excision.

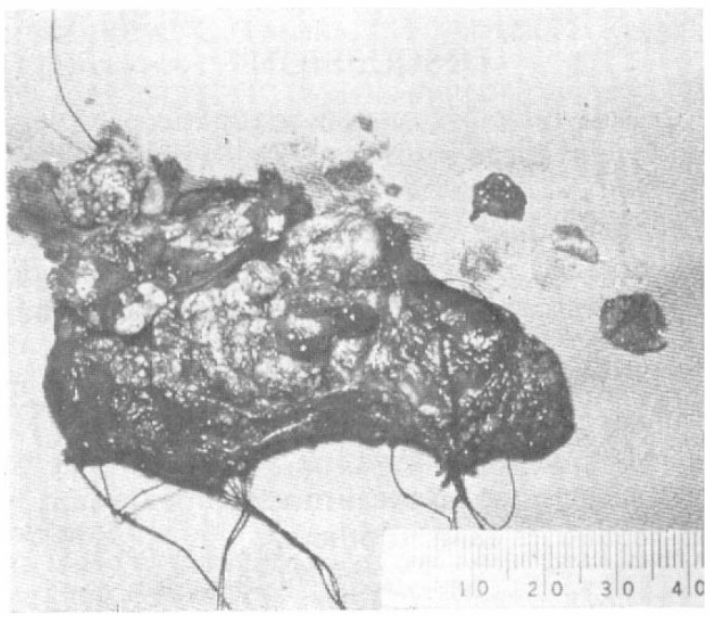

FIG. 7

Specimen of an ependymonia of filum terminale after removal. 
Spinal Cord Tumours. Thirteen cases of paraplegia due to spinal cord compression were treated in the Department of Orthopaedic Surgery. Three were due to secondaries. The remaining nine were either meningiomas or neurofibromas except for two ependymomas and one dermoid cyst. One case, a girl of I2 years is particularly interesting. Her symptoms manifested after a fall from a bicycle. Owing to this unfortunate red herring, it took 2 years for her to seek admission. Figure 5, A and B shows the size of the neurofibroma at operation, and after removal. Her paraplegia recovered completely.

Another interesting case is that of a child treated as a spina bifida for urinary incontinence and weakness of the lower extremities prior to admission to hospital. With excision of a large dermoid cyst, she recovered completely (fig. 6).

There have been two ependymomas of the filum terminals. One was encapsulated while the other was not. The former was treated by surgery alone and has been left with limited weakness in $S_{1 r}$ and $S_{2 r}$ segments. The other case had excision (fig. 7) as thoroughly as possible followed by deep X-ray therapy. An uneventful recovery was made and the patient has been free of recurrence for the past 12 months.

Hansen's Disease. Forty-two patients with paraplegic problems were admitted for treatment. Common problems were non-healing plantar ulcers due to the patients being unable to appreciate minute fractures of the tarsal bones. Here, neglect disorganises the normal pattern of weight transmission, hence the tendency to ulceration. Posterior tibial transfer through the interosseous membrane for dropped feet was the commonest corrective surgical procedure.

Spina Bifida. Seven patients were admitted during this period, one of whom was associated with congenital scoliosis but with plantar grade feet. Surgery in the remainder has been in an effort to establish plantar grade feet. Soft tissue releases with or without a triple arthrodesis, or wedge tarsectomy have been used. Fortunately this condition has not proved to be a major problem.

\section{DISCUSSION}

A study of the causative factors of non-traumatic paraplegia has shown that the major problems occur largely in patients with poliomyelitis and spinal tuberculosis.

In developed countries these conditions are a thing of the past. Many of the patients with poliomyelitis need not have had surgery if adequately cared for initially. With mass immunisation just started, the incidence could be further reduced.

Spinal tuberculosis too, will become less in the years to come with the intensive anti-tuberculosis programmes being carried out.

In all categories of patients reviewed it is evident that the need for early diagnosis and prompt treatment is an ideal much to be desired. This being more so in some developing countries than in others.

\section{SUMMARY}

I. One hundred and forty-one patients with non-traumatic paraplegia were reviewed. 
2. The common causative factors and the problems arising were evaluated.

3. Management of the clinical problems were described.

4. The need for prevention and early treatment has been stressed.

\section{REFERENCES}

ANDRE, T. (1956). Studies on the distribution of tritium labelled dehydrostreptomycin and tetracyline in the body. Acta radiol. Suppl. $\mathbf{1 4 2 .}$

Barcley, W. R., Elbert, R. H., Leroy, G. V., Manthri, R. W. \& Roth, L. J. (I953). Distribution and excretion of radio active isotope in tuberculous patients. F. Amer. med: Ass. I 5I, I384.

Cauchoix, J. \& Benet, J. P. (1957). Ann. roy. Coll. Surg. Engl. $21,237$.

Craig, J. J. (1967). Cerebral Palsy Modern Trends in Orthopaedics, pp. 44. Ed. W. D. Graham. London: Butterworths.

EgGERS, G. W. N. (I952). Transplantation of the hamstring tendons to the femoral condyles to improve extension and flexion in cerebral palsy paralysis. F. Bone ft. Surg. 32A, 827.

Girdlestone, G. R. \& Somerville, E. W. (I952). Tuberculosis of Bones and foints, 2nd ed. pp. I72. London: Oxford University Press.

Goel, M. K. (1967). Treatment of Pott's paraplegia by operation. F. Bone ft. Surg. $49 B(4), 674$.

Grifiths, D., SEDdon, H. J. \& Roaf, R. (1956). Pott's Paraplegia. London: Oxford University Press.

GuIRguIs, A. R. (I967). Pott's paraplegia. F. Bone ft. Surg. 49B(4), 658.

Hever, E. \& Risko, T. (I960). Studies on streptomyicn levels of blood and abscess. Acta tuberc. scand. 38, 40.

Hodgson, A. R., Stock, F. E., FAng., K. E. \& ONG, G. B. (I960). Anterior spinal fusionthe operation approach and pathological findings in 4I2 patients with Pott's disease of the spine. F. Bone ft. Surg. 48, I72.

Hodgson, A. R., Stock, F. E. (I956). Brit. F. Surg. 44, 266.

Hodgson, A. R., Yau, Arthur, C. M. C., KWEN, J. S. \& Kim, D. (I964). A clinical study of 100 consecutive cases of Pott's paraplegia. Clin. Orthop. 36, I 28.

Hodgson, A. R. (I965). Correction of fixed spinal curves-a preliminary communication. f. Bone Ft. Surg. 47A, I22I.

Hodgson, A. R., YAU, ARThUR, C. M. C. (I967). Pott's paraplegia-a classification based on living pathology. Paraplegia, 5(I), I.

Katayama, R., Itami, Y., OYA, K., Tanaka, J. \& Maruno, E. (1930). The chemotherapy of bone and joint tuberculosis. Ann. Tuber. 5, 59.

KIRKALDY, W. W. H. \& GlYN, T. T. (I965). Anterior approaches in the diagnosis and treatment of infection of the vertebral bodies. F. Bone Ft. Surg. 47A, 87 .

KIRKALDY, W. W. H. \& GLYN, T. T. (I965). The surgical approaches to vertebral bodies. F. roy. Coll. Surg. Edin. I0, Io9.

LinDBERG, L. (1967). Experimental skeletal tuberculosis in the guinea pig. Acta. orthop. scand. Suppl., 98.

Menard, V. (I900). Etude Pratique Sur Le Mal De Pott. Paris: Masson Et Cie.

Pollock, G. A. \& ENGLish, T. A. (1967). Transplantation of hamstring muscle in cerebral palsy. F. Bone ft. Surg. 4IB, 80.

Pотт, P. (I779). Remarks on that kind of palsy of the lower limbs which is frequently found to accompany a curvature of the spine and is supposed to be caused by it, together with its method of cure. London.

SEDDON, H. J. (I935). Pott's paraplegia prognosis and treatment. Brit. F. Surg. 22, 769.

SHERRARD, W. J. W. (I944). Posterior ilio-psoas transplantation in the treatment of paralytic dislocation of the hip. F. of Bone and ft. Surg. 46B, 42.

SHERRARD, W. J. W. (I969). Paralysis upper and lower motor neurone I77. Ed. Charles Rob and Rodney Smith. London: Butterworths.

Silva, J. (1958). Tuberculosis of bones and joints. Ceylon Med. F. 4(3), 223.

Silva, J. F. (1964). Pott's paraplegia in Ceylon. f. Int. Coll. Surg. 42(2), I69.

Silva, J. F. (I97I). Orthopaedic problems in developing countries. Orthopaedics, Oxford, vol. 4 , No. 2, 73 . 
Sorrel, E. \& Sorrel, DejuIne, Y. (I923). Richerches sur la transit du upiodol par voie sousarch-noididience claus les differentes formes de paraplegie potique. Rev. neurol. Paris, 2, 88.

Thоmson, S. B. (I966). Indications for surgery in the lower limbs of the cerebral palsied child development. Med. Child Neurol. 8, 987.

Wilkinson, M. C. (I954). Chemotherapy of tuberculosis of bones and joints. F. Bone Ft. Surg. 36B(I), 23.

WILKINSON, M. C. (I955). The treatment of tuberculosis of the spine by eraceration of the paravertebral abscess and currettage of the vertebral bodies. $\mathcal{F}$. Bone $\mathcal{F}$ t. Surg. $\mathbf{3 7} \mathbf{B}(\mathbf{3}), 382$. 